\title{
AN APPROACH FOR DETERMINING THE EXTENT OF CONTRIBUTION OF CONSTRUCTION PROJECT FEATURES TO ACCIDENT CAUSATION
}

\author{
DOI: https://doi.org/10.1016/j.ssci.2010.03.001
}

Patrick Manu, Nii Ankrah, David Proverbs and Subashini Suresh

School of Engineering and the Built Environment, University of Wolverhampton, Wolverhampton, WV1 1SB, UK

\begin{abstract}
In the pursuit of Health and Safety (H\&S) improvement within the UK construction industry, several studies have been conducted to identify accident causal factors to enable the development of accident prevention measures. Adding to such studies, a critique of $H \& S$ literature demonstrates that construction project features $(\mathrm{CPFs})$ such as the nature of project, method of construction, site restriction, project duration, procurement system, design complexity, level of construction, and subcontracting contribute to accident causation and that their contribution is through the introduction of proximal accident causal factors into the construction process. However, the extent of this contribution by these CPFs remains sparingly known and requires further investigation. The study provides this insight by indicating that the extent to which CPFs contribute to accident causation is influenced by two factors; the extent to which the proximal factors contribute to accident causation; and the extent to which the proximal factors are prevalent with/within the CPFs. In line with this fresh insight, an approach for determining the extent to which CPFs contribute to accident causation is put forth. The approach proposes to use a qualitative-quantitative rating scale to determine the two determinant factors and then combine them using a mathematical formula to obtain the extent to which CPFs contribute to accident causation. By this approach the grey areas in literature concerning the extent to which CPFs contribute to accident causation will be illuminated and by that contribute to improvement in construction accident prevention.
\end{abstract}

Keywords: distal accident factors, health and safety, proximal accident factors, rating scale.

\section{Introduction}

The construction industry is one of the industries having the challenge of poor H\&S performance. Studies in several countries such as Korea, China, Turkey, Finland, USA, etc have attributed a high number of adverse H\&S outcomes to the construction industry (cf. Huang et al. (2003), Perttula et al. (2003), Colak et al. (2004), Im et al. (2009), and Yung (2009)), and this state of affairs needs redressing as it dents the reputation of the construction industry (Kartam, 1995).

Like these construction industries, the UK construction industry has persistently been one of the worst industries in the UK in terms of H\&S performance despite its socio-economic benefits (cf. Health and safety Executive (HSE) (2009a)). Sadly, as noted by the HSE (2009b), this implies that associated with the socio-economic benefits derived from the industry is unwanted 'cost' (such as fatalities, major injuries, over-three-day injuries, diseases, etc), and this state of affairs has been (and being) persistently challenged through several efforts (cf. the Revitalising Health and Safety Initiative (Department of the Environment, Transport and the Regions, 2000) and the report, 'One Death is Too Many' (Donaghy, 2009)). In the pursuit of H\&S improvement within the industry, several studies have been conducted to identify causal factors in construction accidents with the aim of enabling the development of accident prevention measures. In seeking 
to contribute to such studies, this study critiques H\&S literature to reveal the contribution of construction project features (CPFs) to accident causation and the knowledge gap relating to the extent to which they contribute to accident causation. In order to unravel the knowledge gap, this study puts forth an approach for determining the extent to which CPFs contribute to accident causation.

\section{The contribution of construction project features to accident causation}

CPFs such as the nature of project, method of construction, site restriction, project duration, procurement system, design complexity, level of construction, and subcontracting contribute to accident causation on projects (cf. HSL (1999), McKay et al. (2002), Loughborough University and UMIST (2003), Gambatese et al. (2008) and HSE (2009b)). These CPFs are organisational, operational, and physical attributes that characterise construction projects, and they emanate from the client's brief, project management decisions and design decisions. Like other distal/originating influences in construction accidents, the above-mentioned CPFs are high level determinates of the nature, extent and existence of immediate causes of accidents (Suraji et al., 2001; Haslam et al., 2005). This distal causal influence of CPFs is demonstrated by the following critique of accident causation literature and other H\&S literature within the UK. In exploring the contribution of CPFs to accident causation, it is acknowledged that the above enlisted CPFs may not be exhaustive. Other CPFs which inherently influence accidents could thus be identified to add unto this insight of the accident causal influence of CPFs.

\subsection{Nature of project}

The nature of project (i.e. new work, repair/refurbishment/maintenance, and demolition) is usually determined by the client's brief. The UK Office for National Statistic (ONS) (ONS, 2009) indicates that compared to new work, repair and refurbishment work constitute a fairly consistent proportion of approximately $45 \%$ of the industry's output. The Health and Safety Executive (HSE) Construction Intelligence Report (HSE, 2009b), however demonstrates that refurbishment and repair work constitutes a fairly consistent proportion of fatal accidents at around $50 \%$. Refurbishment and repair work therefore accounts for a disproportionate percentage of fatal accidents. This trend is attributable to the fact that, the hazards during refurbishment are more uncertain and complex, and hence difficult to observe and evaluate than the hazards on new works (cf. Egbu (1999) and Loughborough University (2006)). Like refurbishment work, demolition work shares similar attributes and is also a hazardous operation responsible for accidents (Hughes and Ferrett, 2008). Hazards such as falling debris, pre-mature collapse of element/structures, dust and fumes, asbestos, noise and vibration, and electric shock are common in demolition and refurbishment work (Loughborough University, 2006; Hughes and Ferrett, 2008), and given that these hazards are uncertain and complex, it is only consequential that refurbishment work and demolition work are more dangerous than new work, as mentioned by Loughborough University and Milan Polytechnic (2004) and Loughborough University (2006).

\subsection{Method of construction}

Studies have pointed to the contribution of method of construction (as determined by the designer) to accident causation (cf. Gibb (1999, 2001), McKay et al. (2002), Loughborough University and UMIST (2003) and Wright et al. (2003)). This is influenced by the extent of manual handling which makes up one-third of all construction accidents in the UK (HSE, 
2009b). Outside of the UK construction industry, Perttula et al. (2003) in Finland, similarly attributed manual handling to a third of the accidents in their study. The conventional on-site (traditional in-situ) method, compared to pre-assembly (off-site fabrication), involves extensive manual handling and therefore introduces a lot of manual handling hazards and thus implying a causal link to manual handling injuries. Research by Gibb (2001) found that because preassembly brought the construction site into the factory where the environment is more controllable, safety, productivity and quality could be improved. The Strategic Forum for Construction (2002), McKay et al. (2002), Loughborough and UMIST (2003), and Wright et al. (2003) have also underscored the H\&S benefits of using pre-assembly construction.

\subsection{Site restriction}

Compared to an unrestricted site, a restricted site (i.e. a site where the floor area uncovered by the structure to be constructed is much smaller than the floor area to be covered by the structure) provided by the client would imply insufficient space on site, and hence limited or congested space for the operatives, plants, machines, equipment, and storage on site (Loughborough University and UMIST, 2003). A restricted site would thus influence accidents as a result of the site congestion it introduces which has been a persistent cause of accidents (cf. Entec UK Ltd (2000), Loughborough University and UMIST (2003) and Loughborough University (2009)). Congested site conditions would imply insufficient working space, constricted room for vehicle manoeuvrability and difficult access to drop-off points, possibly resulting in the need for double handling of materials, all of which have safety implications as mentioned by Loughborough University and UMIST (2003). Congested site conditions could also influence accidents resulting from a worker being struck by a moving vehicle and by a moving (including flying/falling) objects which are among the main causes of fatal accidents as indicated by the HSE (2009).

\subsection{Project duration}

During construction, it is possible that the anticipated/targeted construction duration set by the project planners may eventually not be exactly the actual duration spent as there could be time over-runs or early completion. However, this planned duration, as it represents a time span, has the potential to influence accident occurrence. A constrained duration set by the client or the project management team results in time pressure at the construction phase with subsequent problems such as trade overlap, crowded work space, reduced attention to detail, and the prioritising of production over safety which influence accident occurrence (Mayhew \& Quinlan, 1997; Loughborough University and UMIST, 2003; Loughborough University, 2009).

\subsection{Design Complexity}

The influence of design on accident causation has been well echoed through out the UK construction industry (cf. Entec UK Ltd. (2000), Loughborough University and UMIST (2003), Wright et al. (2003) and Donaghy (2009)), hence the existence of the UK Construction (Design and Management) Regulations 2007 (CDM 2007). The findings of Loughborough University and UMIST (2003) indicated that an increased desire for aesthetic qualities inhibit the ease of building which in itself induces safety hazards. As part of the research informing the Donaghy Report (2009), Loughborough University (2009), again mentioned poor design for buildability as a causal factor in construction fatalities. Designs that are complex (having intricate aesthetic qualities) therefore tend to have a greater potential to influence accident occurrence as such designs inhibit buildability (Loughborough University and UMIST, 2003). 


\subsection{Subcontracting}

Several studies, both within and outside of the UK construction industry have identified subcontracting as a causal factor in construction accidents. In countries such as Spain, Malaysia, Philippine, Poland, Hong Kong, China, and Australia, subcontracting has been associated with adverse H\&S outcomes in the construction industry (cf. Byrne and van der Meer (2001), ILO (2001), Wong and So (2002), and Yung (2009)). Similarly in the UK, the accident causal influence of subcontracting has been reported over the years (cf. Mayhew and Quinlan (1997), HSL (1999), Loughborough University and UMIST (2003), Ankrah et al. (2007), Donaghy (2009) and Manu et al. (2009a)). As a distal causal factor, subcontracting could emanate from the pre-construction phase (through decisions by the project planners and client) and/or during the construction phase (by a principal contractor/contractor and client/client representative). Subcontracting inherently introduces fragmentation of the workforce which impedes H\&S management on site (Mayhew and Quinlan, 1997; Loughborough University and UMIST, 2003).

\subsection{Procurement system}

The UK construction industry is complex covering a large number of players (cf. ONS (2008)). In view of this, Entec UK Ltd (2000) reported that there are organisational obstacles which impede H\&S improvement in the industry. Interaction in the supply chain is often divisive rather than supportive and this impedes H\&S improvement (Entec UK Ltd, 2000). Entec UK Ltd (2000) however indicated that, partnering arrangement is perceived as being able to enhance $\mathrm{H} \& \mathrm{~S}$ improvement as it enables the building of close working relationships and it also provides opportunities for discussion, hazard identification and problem solving at the early stage of the project. Another procurement arrangement which is perceived as being able to enhance H\&S improvement is design and build procurement (Loughborough University and UMIST (2003)). Loughborough University and UMIST (2003) in their study into causal factors in construction accidents reported that design and build procurement is perceived as enabling H\&S improvement because the contractual arrangements place the responsibility for both design and construction within a single project team, leading to shared goals, improved communication, and a better environment for new ideas to flourish. Evidently these procurement arrangements promote team integration which is essential for project success (Egan, 1998; Strategic Forum for Construction, 2002; Baiden et al., 2006). Contrary to partnering and design and build procurement, a procurement arrangement that has been identified to have adverse H\&S implications is management contracting (Health and Safety Laboratory (HSL), 1999). Management contracting is considered more problematic than the traditional mode of procurement when addressing the maintenance of good H\&S (HSL, 1999). A critical look at these latter procurement arrangements reveals that management contracting and traditional procurement fragment the project team, thus impeding effective management of H\&S on site.

\subsection{Level of construction}

The level of construction, particularly multi-level/high-level construction greatly involves working at height which accounts for falls from height which also have been responsible for about 50\% of fatal injuries from 1996/97 to 2007/08 (HSE, 2009b). Thus comparing low-level construction to multi-level/high-level construction, multi-level/high-level construction contributes greater to accident causation. Research by Chua and Goh (2005) in Singapore also revealed that underground construction has a higher rate of incidents (i.e. unintentional and undesirable events that may or may not result in an injury) than above-ground construction. 
Although Chua and Goh (2005) did not delve deep into the possible causes of the higher rate of incidents associated with underground construction, it is well known that underground construction involves working in confined space which accounts for adverse H\&S outcomes (cf. Hughes and Ferrett, 2008) hence the existence of the UK Confined Spaces Regulations 1997.

The above review clearly demonstrates that the distal accident causal influence of CPFs is undeniably existent and has severe ramifications. It also underscores the multi-faceted nature of construction accident causation (Behm, 2005; Loughborough, 2009) and also the need to address distal causal factors to ensure sustained improvement in H\&S (Haslam et al., 2005). In the context of achieving H\&S improvement it is important to further explore the contribution of CPFs to accident causation with the aim of gaining deeper insight into the subject, as it is by such understanding that effective accident prevention measures can be developed and implemented (Suraji et al., 2001).

\section{Understanding the extent to which construction project features contribute to accident causation}

As demonstrated by the above review, it is realised that CPFs do not directly cause accidents but do so through other accident causal factors. These other causal factors which directly lead to accidents are termed proximal causal factors (PFs) (Suraji et al., 2001; Haslam et al., 2005), which are closer to accident events than CPFs. CPFs being distal to accident events are thus also termed distal/root/originating causal factors (Suraji et al., 2001; Haslam et al., 2005) and it is by their introduction of the proximal factors that CPFs contribute to accident causation. With CPFs being distal causal factors, they also emanate from the client's brief, design decisions and project management decisions (cf. Suraji et al. (2001), Haslam et al. (2005) and Cheng et al. (2005)). Building on this brief background, the process/pattern by which CPFs contribute to accidents could thus be illustrated as shown in Figure 1.

Due to the remoteness of CPFs from an accident event in the causation process (as shown in Figure 1), their contribution to accidents is latent/subtle and therefore could go unnoticed as noted by Haslam et al. (2005). As demonstrated by the above critique of literature, CPFs contribute by varying extents to accident causation, the extent of which is influenced by the degree of prevalence of the relevant proximal factor(s) with/within CPFs (as shown in Table 1).

To illustrate, subcontracting (multi-layer and single layer) introduces fragmentation of the work force (proximal factor) which causes accident (Mayhew \& Quinlan, 1997; Loughborough \& UMIST, 2003). The degree of prevalence of the proximal factor (fragmentation of the work force) within multi-layer subcontracting and single-layer subcontracting gives an indication of the extent to which multi-layer subcontracting and single-layer subcontracting contribute to accident causation.

A breakdown of this illustration is given below;

Fragmentation of workforce contributes to accident causation.

Fragmentation of workforce is introduced by multi-layer subcontracting and single-layer subcontracting.

Fragmentation of workforce is greater/more prevalent within multi-layer subcontracting than single-layer subcontracting.

Therefore the extent of contribution to accident causation by multi-layer subcontracting, relative to single-layer subcontracting, is higher. 
Comparing CPFs of different kinds (e.g. refurbishment and management subcontracting), literature gives no indication of the extent of relative contribution to accident causation. Table 1 is therefore limited in giving an indication of the extent of relative contribution to accident causation when considering CPFs of different kinds. For instance, Table 1 does not give an indication of the extent of contribution to accident causation by refurbishment in relation to management contracting. This means that the extent of contribution to accident causation illustrated in Table 1 is only the extent of contribution of CPFs to accident causation within the context of CPFs of the same kind. There is therefore no indication of the actual extent of contribution to accident causation which would also allow for relative comparison amongst CPFs of different kinds. This limitation by literature represents a knowledge gap which ought to be interrogated in order to have the full insight of the extent of contribution of CPFs to accident causation. An approach for obtaining the actual extent of contribution of CPFs to accident causation is put forth and explained in the following section. This approach will thus be the means and basis for having full insight into the extent of contribution of CPFs to accident causation, which will be a useful insight for accident prevention (Suraji et al., 2001).

\section{An approach for obtaining the actual contribution of construction project features to accident causation}

Although it is logical to point to the prevalence of a proximal factor with/within a CPF as influencing the extent to which the CPF contributes to accident causation, it can also be argued that the extent to which a CPF contributes to accident causation is first and foremost influenced by the extent to which the related proximal factor causes accidents. This is because it is by reason of the related proximal factor causing accidents in the first place that the CPF is also able to contribute to the causation of accidents as a result of its introduction of the proximal factor. This means that if a proximal factor does not cause accident in the first place, no matter its prevalence with/within a $\mathrm{CPF}$ that $\mathrm{CPF}$ will not contribute to accident causation. Advancing this argument, the extent to which a $\mathrm{CPF}$ contributes to accident causation (represented by ' $\boldsymbol{C}$ ') is therefore a function of;

- the extent to which the related proximal factor contributes to accident causation (represented by ' $\boldsymbol{R}$ ') ; and

- the extent to which the proximal factor is prevalent/common with/within the CPF (represented by ' $r$ ').

This can be expressed mathematically as $\mathbf{C}=f(\boldsymbol{R}, \boldsymbol{r})$.

Applying the method of combination (i.e. multiplication) as used in mathematical risk expressions (cf. Risk \& Policy Analyst Limited (1999 and Hughes and Ferrett (2008)) the above expression can be re-written as, $\mathbf{C}=\boldsymbol{R} \mathbf{x} \boldsymbol{r}$.

This expression having been derived, the next step is to obtain a measure of the two determinant factors, and in that regard a qualitative-quantitative rating scale similar to the one used by Loughborough University (2000) could be very useful. Loughborough University (2000) in a study conducted for the HSE used a qualitative-quantitative rating scale to obtain the extent to which various factors contribute to accident causation. In the study, focus groups rated on a scale of 1 to 5 (from 'Not at all' to 'To a very large degree') the extent to which various factors 
contribute to accident causation. By using a similar qualitative-quantitative rating scale, a rated measure for each of the two determinant factors can be obtained and then applied in the derived expression to obtain the extent to which a CPF contributes to accident causation. The entire approach is illustrated below using two kinds of CPFs: procurement system and subcontracting.

\section{Stage 1}

Determine the extent to which the proximal factor associated with subcontracting (i.e.

fragmentation of the workforce) and the proximal factor associated with procurement system (i.e. fragmentation of the project team) contribute to accident causation using the rating scale below .

Scale: $0=$ Not at all, $1=$ Low, $2=$ Moderate, $3=$ High, $4=$ Very High .

Result:

Subcontracting $=R_{S}$

Procurement system $=R_{P}$

Where $R_{S}$ and $R_{P}$ are rates indicating the extent to which the proximal factors associated with subcontracting and procurement system respectively, contribute to accident causation.

\section{Stage 2}

Using the above scale, determine;

- the extent to which fragmentation of the workforce is prevalent within multi-layer subcontracting and single-layer subcontracting; and

- the extent to which fragmentation of the project team is prevalent within management contracting, traditional procurement, and design and build procurement.

Result:

Multi-layer subcontracting $=r_{S I}$

Single-layer subcontracting $=r_{S 2}$

Management contracting $=r_{P 1}$

Traditional procurement $=r_{P 2}$

Design and Build procurement $=r_{P 3}$

Where;

- $r_{S 1}$ and $r_{S 2}$ are rates indicating the extent to which fragmentation of work force is prevalent within multi-layer subcontracting and single-layer subcontracting respectively; and

- $\quad r_{P 1}, r_{P 2}$ and $r_{P 3}$ are rates indicating the extent to which fragmentation of the project team is prevalent within management contracting, traditional procurement, and design and build procurement respectively.

The results for stage 2 only gives an indication of the extent to which CPFs of the same kind contribute to accident causation in line with Table 1. To obtain the actual extent of contribution to accident causation, the rates for stage 1 will then have to be applied to their corresponding rates in stage 2 as illustrated below.

The extent of contribution to accident causation $(C)$ by;

Multi-layer subcontracting $=R_{S} \times r_{S I}$

Single-layer subcontracting $=R_{S} \times r_{S 2}$

Management subcontracting $=R_{P} \times r_{P I}$ 
Traditional procurement $=R_{P} \times r_{P 2}$

Design and Build procurement $=R_{P} \times r_{P 3}$

\subsection{Reflection on the approach}

Using hypothetical values of rates will aid a better understanding of the above approach. Taking for instance management contracting and multi-layer subcontracting, Table 2 below indicates rates for stage 1 (i.e. the extent to which the related proximal factors contribute to accident causation) and stage 2 (i.e. the extent to which the proximal factors are prevalent within the CPFs).

For management contracting, this simply means that the proximal factor (fragmentation of workforce) contributes to accident causation by a measure of 4 and the degree of this measure that is within management subcontracting is 4. Therefore the extent of contribution of management contracting to accident causation will be, 4 x $4=16$. Similarly, the extent of contribution of multi-layer subcontracting to accident causation will be, $3 \times 4=\mathbf{1 2}$. By this, the contribution of management contracting to accident causation will be seen to be higher than that of multi-layer subcontracting. By using this approach, the actual extent of contribution of a CPF to accident causation (which allows for relative comparison among CPFs of the same kind and of different kind) will thus be obtained and this will give a better understanding of the varying extent to which CPFs contribute to accident causation. By this accident prevention measures can be prioritised to reflect relative extent of contribution to accident causation.

Having established an approach for determining the actual extent of contribution of CPFs to accident causation, the next step then is to undertake research to obtain practical rates for subsequent application using the above derived expression in order to obtain the extent to which $\mathrm{CPF}$ contribute to accident causation. Clearly, the insight such a study will give will contribute towards improvement in construction accident prevention.

\section{Conclusion}

The above critique of accident causation literature has clearly demonstrated that CPFs undeniably contribute to accident causation and that the extent to which they contribute to accident causation varies. Beyond creating this awareness, the study has revealed the knowledge gap concerning the extent to which CPFs contribute to accident causation. The study unravels the knowledge gap by demonstrating that the extent to which CPFs contribute to accident causation is not only dependent on the degree of prevalence of the proximal accident causal factors within CPFs but it is primarily influenced by the extent to which the proximal factors contribute to accident causation. To enable the determination of the extent to which CPFs contribute to accident causation, the study has presented a novel systematic approach which uses a mathematical expression with its input provided by a qualitative-quantitative rating scale. By this approach the grey areas in literature concerning the extent to which CPFs contribute to accident causation will be illuminated and by that contribute to improvement in construction accident prevention. With CPFs being distal causal factors, using this approach to determine their extent of contribution to accident causation also suggests that this approach could potentially be useful in determining the extent to which other distal causal factors contribute to accident causation. 


\section{References}

Ankrah, N. A., Proverbs, D. \& Debrah, Y. (2007) Improving satisfaction with construction projects outcomes: the role of culture. Construction Management and Economics $25^{\text {th }}$ Anniversary Conference. Reading, UK, Construction Management and Economics.

Baiden, B. K., Price, A. D. F., Dainty, A. R. J. (2006) The extent of team integration within construction projects. International Journal of Project Management, 24, 13-23.

Behm, M. (2005) Linking construction fatalities to the design for construction safety concept. Safety Science, 43, 589-611.

Byrne, J. \& Van Der Meer, M. (2001) The construction industry in Spain: Flexibilisation and other corporatist illusions. International Conference on Structural Change in the Building Industry's Labour Market, Working Relations and Challenges in the Coming Years. Institut Arbeit und Technik, Gelsenkirchen, Germany.

Cheng, J., Proverbs, D. G., Oduoza, C. \& Fleming, C. (2005) A conceptual model towards the measurement of construction client satisfaction. In: Khosrowshahi, F. (Ed.), 21 st Annual ARCOM Conference, 7-9 September 2005, SOAS, University of London. Association of Researchers in Construction Management.

Chua, D. K. H. \& Goh, Y. M. (2005) Poisson model of construction incident occurrence. Journal of Construction Engineering and Management, 131, 715-722.

Colak, B., Etiler, N., \& Bicer, U. (2004). Fatal occupational injuries in the construction sector in Kocaeli, Turkey, 1990-2001. Industrial Health, 42, 424-430.

Department of the Environment, Transport and the Regions (2000) Revitalising health and safety- Strategy Statement. Department of the Environment, Transport and the Regions.

Donaghy, R. (2009) One death is too many - Inquiry into the underlying causes of construction fatal accidents: Report to the secretary of state for work and pensions.

Egan, J. (1998) Rethinking construction. London, Department of the Environment, Transport and the Regions.

Egbu, C.O. (1999) Skills, knowledge and competencies for managing construction refurbishment. Construction Management and Economics, 17, 29-43.

Entec UK Ltd. (2000) Construction health and safety for the new millennium. HSE Contract Research Report 313/2000. HSE. 
Gambatese, J. A., Behm, M. \& Rajendran, S. (2008) Design's role in construction accident causality and prevention: Perspectives from an expert panel. Safety Science, 46, 675-691.

Gibb, A. G. F. (1999) Principles in off-site fabrication, Caithness, Whittles.

Gibb, A. G. F. (2001) Standardization and pre-assembly - distinguishing myth from reality using case study research. Construction Management and Economics, 19, 307-315.

Haslam, R. A., Hide, S. A., Gibb, A. G. F., Gyi, D. E., Pavitt, T., Atkinson, S. \& Duff, A. R. (2005) Contributing factors in construction accidents. Applied Ergonomics, 36, 401-415.

HSE (2009a) Statistics on fatal injuries in the workplace 2008/09

www.hse.gov.uk/statistics/fatalinjuries.htm. (07/12/09).

HSE (2009b) Construction intelligence report: Analysis of construction injury and ill-health intelligence. www.hse.gov.uk/construction/pdf/conintreport.pdf. (07/12/09).

HSL (1999) The impact of procurement and contracting practices on health and safety -A review of literature. Report: RAS/99/02. HSL.

Huang, X. \& Hinze, J. (2003) Analysis of construction worker fall accidents. Journal of Construction Engineering and Management, 129, 262-271.

Hughes, P. \& Ferrett, E. (2008) Introduction to health and safety in construction, $3^{\mathrm{RD}}$ Edition, Oxford, Elsevier Ltd.

ILO (2001) The construction industry in the twenty-first century: Its image, employment prospects and skill requirements. Geneva, ILO.

Im, H.-J., Kwon, Y.-J., Kim, S.-G., Kim, Y.-K., Ju, Y.-S. \& Lee, H.-P. (2009) The characteristics of fatal occupational injuries in Korea's construction industry, 1997-2004. Safety Science. [In press, doi:10.1016/j.ssci.2008.11.008].

Kartam, N. A. (1995) Integrating safety and health performance into construction CPM. Journal of Construction Engineering and Management. 124, 121-126.

Loughborough University (2000) Focus group analysis. Draft Report to HSE.

Loughborough University (2006) Avoiding structural collapses in refurbishment - A decision support system. HSE Research Report 204, HSE.

Loughborough University (2009) Phase 2 Report: Health and safety in the construction industry: Underlying causes of construction fatal accidents -External research. HSE.

Loughborough University \& Milan Polytechnic (2004) Health and safety in refurbishment involving demolition and structural instability. HSE Research Report 204. HSE. 
Loughborough University \& UMIST (2003) Causal factors in construction accidents. HSE Research Report 156. HSE.

Manu, P., Ankrah, N., Proverbs, D., Suresh, S. \& Callaghan, E. (2009) Subcontracting versus health and safety: an inverse relationship. Proceedings of CIB W099 Conference 2009. Melbourne, Australia. CIB.

Mayhew, C. \& Quinlan, M. (1997) Subcontracting and occupational health and safety in the residential building industry. Industrial Relations Journal, 28, 192-205.

McKay, L. J., Gibb, A. G. F., Haslam, R. \& Pendlebury, M. (2002) Implications for the effect of standardization and pre-assembly on health, safety and accident causality- preliminary results. In: Greenwood, D. (Ed.) 18th Annual ARCOM Conference. University of Northumbria, Association of Researchers in Construction Management.

ONS (2008) Construction statistics annual: 2009 Edition. ONS.

ONS (2009) Output and employment in the construction industry - 1st quarter 2009. Statistical Bulletin. ONS.

Perttula, P., Merjama, J., Kiurula, M. \& Laitinen, H. (2003) Accidents in materials handling at construction sites. Construction Management and Economics, 21, 729-736.

Risk \& Policy Analyst Ltd. (1999) Risk ranking for small and medium enterprises. HSE Contract Research Report 256/1999.HSE

Strategic Forum for Construction (2002) Accelerating change: a report by the Strategic Forum for Construction, chaired by Sir John Egan, London, Rethinking Construction.

Suraji, A., Duff, A. R. \& Peckitt, S. J. (2001) Development of a causal model of construction accident causation. Journal of Construction Engineering and Management, 127, 337-344.

Wong, F. \& So, L. (2002) Restriction of the multi-layers subcontracting practice in Hong Kong Is it an effective tool to improve safety performance of the construction Industry? 3rd International Conference of CIB Working Commission 099 - Implementation of safety and health on construction sites: One country - two systems. Hong Kong, CIB.

Wright, M., Bendig, M., Pavitt, T. \& Gibb, A. (2003) The case for CDM: better safer design-a pilot study. HSE Research Report 148. HSE.

Yung, P. (2009) Institutional arrangements and construction safety in China: an empirical examination. Construction Management and Economics, 27, 439 - 450. 


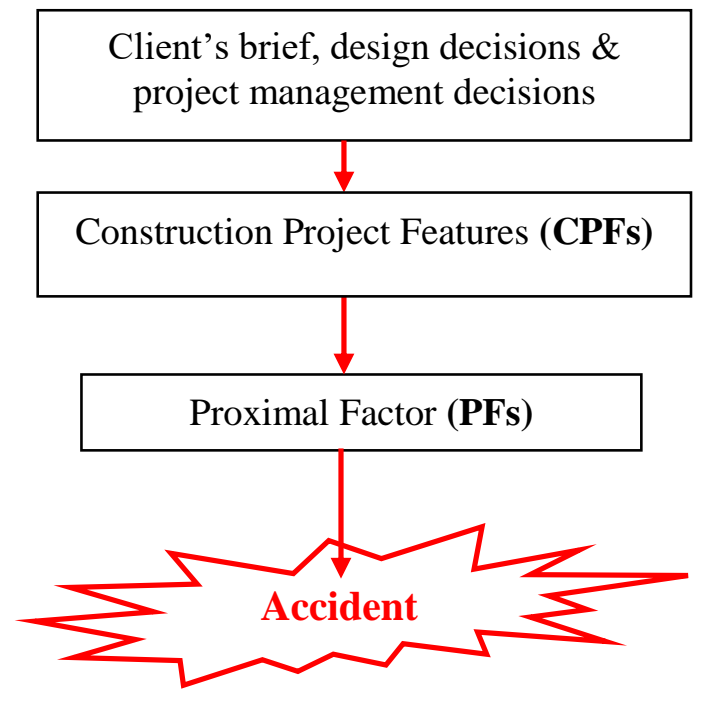

Figure 1: Model of contribution of CPFs to accident causation (Adapted from Suraji et al. (2001) and Haslam et al. (2005)) 
Table 1: An illustration of the extent of contribution of CPFs to accident causation

\begin{tabular}{|c|c|c|}
\hline \multirow[t]{2}{*}{ Proximal Factors } & \multicolumn{2}{|c|}{$\begin{array}{c}\text { Extent of Contribution of CPF to Accident Causation } \\
\text { Prevalence of proximal factor within } C P F\end{array}$} \\
\hline & Low & High \\
\hline $\begin{array}{l}\text { Uncertainty and } \\
\text { complexity of hazards } \\
\text { (Egbu, 1999; } \\
\text { Loughborough University, } \\
\text { 2006) }\end{array}$ & New work & $\begin{array}{l}\text { Refurbishment } \\
\text { Demolition }\end{array}$ \\
\hline $\begin{array}{l}\text { Manual handling } \\
\text { (McKay et al., 2002; } \\
\text { Wright et al., 2003) }\end{array}$ & Pre-assembly construction & Conventional on-site construction \\
\hline $\begin{array}{l}\text { Site congestion } \\
\text { (Loughborough University } \\
\text { and UMIST, 2003; } \\
\text { Loughborough University, } \\
\text { 2009) }\end{array}$ & Unrestricted site & Restricted site \\
\hline $\begin{array}{l}\text { Time pressure } \\
\text { (Loughborough University } \\
\text { and UMIST, 2003; } \\
\text { Loughborough University, } \\
\text { 2009) }\end{array}$ & Unconstrained duration & Constrained duration \\
\hline 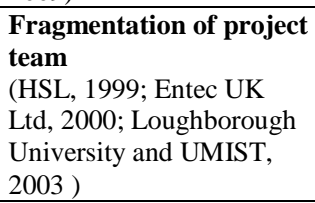 & $\begin{array}{l}\text { Design and build procurement } \\
\text { Partnering }\end{array}$ & Management contracting \\
\hline $\begin{array}{l}\text { Difficulty in constructing } \\
\text { (Loughborough University } \\
\text { and UMIST, 2003; } \\
\text { Loughborough University, } \\
\text { 2009) }\end{array}$ & $\begin{array}{c}\text { Simple Design } \\
\text { (Simple aesthetic qualities) }\end{array}$ & $\begin{array}{c}\text { Complex Design } \\
\text { (Intricate aesthetic qualities) }\end{array}$ \\
\hline $\begin{array}{l}\text { Working at height / } \\
\text { Confined space } \\
\text { (Hughes and Ferrett, 2008; } \\
\text { HSE, 2009b) }\end{array}$ & Low-level construction & $\begin{array}{l}\text { Multi/High-level construction } \\
\text { Underground construction }\end{array}$ \\
\hline $\begin{array}{l}\text { Fragmentation of work } \\
\text { force } \\
\text { (Mayhew and Quinlan, } \\
\text { 1997; HSL, 1999; } \\
\text { Loughborough University } \\
\text { and UMIST, 2003) }\end{array}$ & Single-layer subcontracting & Multi-layer subcontracting \\
\hline
\end{tabular}


Table 2: Rates for management contracting and multi-layer subcontracting

\begin{tabular}{|l|c|c|c|c|}
\hline \multirow{2}{*}{ Rate } & \multicolumn{2}{|c|}{ Management contracting } & \multicolumn{2}{c|}{ Multi-layer subcontracting } \\
\cline { 2 - 5 } & Stage 1 & Stage 2 & Stage 1 & Stage 2 \\
\hline
\end{tabular}

